UDK 78: 811.163.42’373.46

Prethodno priopćenje

Rukopis primljen 8. VII. 2018.

Prihvaćen za tisak 4. XII. 2018.

Evaine Le Calvé Ivičević

Filozofski fakultet Sveučilišta u Zagrebu

eivicevi@ffzg.hr

Iva Pranjković

ivapranjkovic@gmail.com

\title{
MALI KORAK PREMA USUSTAVLJENJU TERMINOLOGIJE ASPEKTOLOGIJE NA HRVATSKOME JEZIKU
}

Brojni radovi posvećeni glagolskom vidu u različitim slavenskim, ali i u drugim jezicima u kojima ova kategorija nije morfološki obilježena, proizveli su obilje naziva te doveli do nejasnoća koje predstavljaju prepreke u razvoju aspektologije. U tradiciji radova koji opisuju glagolski vid i aspektna značenja u slavenskim jezicima pojedini se nazivi redovno pojavljuju, dok noviji nazivi nemaju nužno isto značenje pod perom svih autora koji ih koriste. No uz iznimku rijetkih članaka koji opisuju pojedine teme, nijedan autor nakon Đure Grubora nije pokušao razraditi cjelovito nazivlje koje bi udovoljilo potrebama za opisom aspektnih značenja u hrvatskome. Iz toga proizlazi potreba za preispitivanjem postojećih naziva $\mathrm{i}$ definicija pojmova koje označavaju kako bismo mogli ponuditi precizno osnovno nazivlje kao poticaj za nastavak istraživanja o aspektologiji. U prvom dijelu istraživanja ponudit ćemo pregled do sada korištenih naziva i pojmova u radovima posvećenim glagolskom vidu. U drugom dijelu predložit ćemo usustavljeno osnovno nazivlje i harmonizirane definicije u njemu označenih pojmova.

\section{Uvod}

Brojni radovi posvećeni glagolskom vidu u slavenskim, ali i u drugim jezicima u kojima ova kategorija nije morfološki obilježena, proizveli su obilje naziva, odnosno sustava naziva koji se razlikuju ovisno o pojedinom opisu. To obilje proizvelo je nejasnoće koje predstavljaju prepreke u razvoju aspektologije. Uz 
iznimku rijetkih članaka koji opisuju pojedine teme (Mršić 1999, Novak Milić 2010), hrvatski jezikoslovci nisu pridonijeli usustavljenju opisa glagolskog vida kao domene proučavanja tako da nakon Đure Grubora (1953a, 1953b) nijedan autor nije pokušao razraditi cjelovito nazivlje koje bi udovoljilo potrebama za opisom aspektnih značenja u hrvatskome i na hrvatskom jeziku te su se u hrvatskoj literaturi nejasnoće zadržale kako u definicijama pojmova tako i u samoj srži jezičnog nazivlja (Novak Milić 2010: 131). Iz toga proizlazi potreba za preispitivanjem postojećih naziva i definicija pojmova koje označavaju kako bismo mogli ponuditi precizno osnovno nazivlje kao poticaj za nastavak istraživanja o aspektologiji. Namjera je ovog rada, baziranog na korpusu od pedesetak radova tridesetak autora, odnosno ukupno sedamdesetak naziva/pojmova, napraviti mali korak prema ostvarivanju tog cilja, tako da ćemo ponuditi skup pojmova s pripadajućim definicijama i naziva potrebnih za opisivanje glagolskog vida i aspektnih značenja na hrvatskome. U prvom dijelu ponudit ćemo pregled do sada korištenih naziva i pojmova u radovima posvećenim glagolskom vidu. U drugom dijelu nastojat ćemo uvesti korisne i, s hrvatskoga gledišta, nove opisne elemente, uključiti koncepte aspektnih značenja, glagolskog pojma i teličnosti, predložiti preoblikovanje razlikovanja svršene i nesvršene radnje te naposljetku predstaviti ekvipolenciju vidske opreke.

\section{Postojeći pojmovi, njihove definicije i nazivi}

Glagolski vid (glagolski aspekt) ${ }^{1}$ u hrvatskome jest, jednako kao i u drugim slavenskim jezicima, gramatička kategorija „uključen[a] u samoj glagolskoj osnovi" (Jonke 1964: 28), koja spada u univerzalnu kategoriju aspektnosti (Novak Milić 2010), ali nije istoznačna s njome, a sastoji se od morfološke opreke, leksičko-gramatičke, odnosno leksičko-morfološke razlike (Pranjković 2003: 11). Vid je (zajedno s (ne)prijelaznošću) ,unutrašnja glagolska kategorija” (Pranjković 2003: 11) te „osobina naših glagola, da se oblikom može izreći svršenost ili nesvršenost radnje" (Težak i Babić 2009: 138-139), pomoću svršenoga i nesvršenoga člana koji među sobom tvore opozicijsko jedinstvo (Brlobaš 2007: 28),

\footnotetext{
Termin vid je dakako općeprihvaćen. Ipak, preporučili bismo korištenje njegova suparnika aspekt, koji otvara mogućnost raspolaganja potpunijim tvorbenim gnijezdom (aspekt/aspektni/dvoaspektni/aspektnost/ aspektolog/aspektologija), što je poželjno za dosljednost opisa sustava.
} 
stoga se može reći da je glagolski vid dvojčan (Babić i dr. 2007: 499), odnosno da počiva na vidskoj razlici (Mønnesland 2003: 25), za koju držimo da ju je točnije pojmiti kao binarnu vidsku opreku. Stoga ne čudi što trećina naziva raspolaže dihotomskim parnjakom.

Za imenovanje vidske opreke raspolažemo s najmanje tri izraza sastavljena od parova naziva: nesvršeni/svršeni vid, ${ }^{2}$ nesvršena/svršena radnja, nesvršeni/ svršeni glagol (Brlobaš 2007: 25). ${ }^{3}$ Prvi par (nesvršeni/svršeni vid) nadovezuje se na pojam glagolske kategorije kao takve, koja sadrži samo dvije gramatičke oznake: svršen i nesvršen (Katičić 2002: 51). Drugi je par (nesvršena/svršena radnja) sporan u smislu da može dovesti u pitanje što to u stvari glagol izražava te, u svakom slučaju, podrazumijeva to da riječ ,radnja” obuhvaća tri vrste predikatne situacije: radnju, stanje i zbivanje. Treći par, premda preuzet u svim suvremenim gramatikama, nije se uvijek jednoglasno prihvaćao. Pojedini autori poput Grubora (1953) dali su prednost paru glagoli vršenja/glagoli izvršsenosti. Pitanje izbora između nesvršeni/svršeni glagol i glagol vršenja/izvršenosti ovisi o definiciji koja se pridaje svršenom i/ili nesvršenom glagolu ili onomu što on izražava.

Kada se radi o glagolima i njihovu vidu, oni se često definiraju prema načinu na koji izražavaju radnju: „Svršeni vid izražava radnju kao cjelinu, obuhvaćenu jednim pogledom (...) Nesvršeni vid ostavlja to obilježje neizraženo, tj. radnja se promatra u procesu bez obzira na početak i kraj, o njima se ništa ne govori, ne promatra se kao zatvorena cjelina" (Babić i dr. 2007: 499), ili jedni u odnosu na druge, kao da ih uvijek nalazimo u paru: „Nesvršeni glagoli imaju nasuprot sebi svršene glagole i, obrnuto, svršeni - nesvršene glagole" (Silić i Pranjković 2005: 56).

Stoga je netočno tvrditi da su svršeni i nesvršeni glagoli konkurentni jer je upotreba jednoga ili drugoga uvijek rezultat izbora. Uz iznimku određenih glagolskih pojmova koji se pojavljuju samo u jednom obliku i u kojima je stoga izbor nemoguć, glagoli najčešće tvore vidske parove, a ponašaju se kao vidski parnjaci unutar para. Hrvatsko nazivlje razlikuje ,prave” vidske parnjake, koji posjeduju

\footnotetext{
U pogledu ove opreke Kravar napominje: ,nazivi ‘nesvršeni’ i ‘svršeni’ glagoli neuspio [su] prijevod s ruskoga, gdje 'soveršennyj' i 'nesoveršennyj' u odnosu na vid znače 'neizvršeni' i 'izvršeni'." (Kravar 1964: 37).

3 Može se primijetiti da je najplodniji korijenski morfem u ovom nazivlju vršs, s 13 termina, koji međutim ne pridonose razvoju bogatog tvorbenog gnijezda, nego se 'sudaraju' jer sudjeluju u različitim sustavima.
} 
identični značenjski sadržaj i oprečni su jedan drugome samo po svojstvima vezanima za njihov vid, te ,neprave” vidske parnjake koji posjeduju samo određenu leksičku bliskost (Raguž 2010: 187). ${ }^{4}$

Kategoriji „pravih” vidskih parnjaka pripadaju: 1. članovi parova čija se svršenost izražava sufiksima (bacati/baciti); 2. članovi prefigiranih parova čija se nesvršenost izražava sufiksima (isplaziti/isplazivati); 3. članovi supletivnih parova (govoriti/reći); 4. članovi koji se unutar para razlikuju samo po naglasku ${ }^{5}$ (poglédati/pògledati, raskidati/ràskidati) (Barić i dr. 2005: 227); 5. članovi parova (pisati/napisati) koji se tvore pomoću obeznačenih prefiksa, koji se nazivaju i praznim prefiksima. Kategoriji „nepravih” vidskih parnjaka pripadaju članovi parova koji se tvore prefiksacijom (brisati/prebrisati) ili sufiksacijom (vikati/ viknuti) koje kao rezultat daju leksičku promjenu.

Skupina glagola bez para, odnosno imperfectiva tantum i perfectiva tantum, se ne navodi u hrvatskim gramatikama. ${ }^{6} \mathrm{U}$ svakom slučaju glagoli bez para u kontekstu funkcioniraju na isti način kao i glagoli s parom te je možda to razlog zbog kojeg u hrvatskome za njih ne postoje posebni nazivi.

U suvremenom hrvatskom svi glagoli imaju morfološki obilježen vid, što ne sprječava postojanje dvovidnih glagola. Dvovidnost označava sposobnost tih glagola, koji se nazivaju i glagolima „,s dva vida” ili „,s dvostrukim vidom”, da „u pojedinom kontekstu [budu] samo jednoga aspekta" (Brlobaš 2007: 31). U svojem proučavanju modalnih glagola Kravar (1957) uvodi, a Mønnesland (2003) preuzima naziv vidski neutralni glagoli kako bi imenovao tu skupinu glagola. Međutim, smatramo da taj naziv ne treba zadržati jer glagoli s dva vida nisu u pravom smislu riječi „,neutralni” utoliko što „ne niječu kategoriju vida” (Babić i dr. 2007: 501), već se mogu ponašati katkad kao nesvršeni, katkad kao svršeni i to ne samo sintaktički, kako primjećuje Mønnesland (2003: 22), već i na razini aspektnih značenja. Ipak, ideja „neutralnosti” dvovidnih glagola iskoristiva je na razini morfološkog ili sintaktičkog opisa ako se uzme u obzir, kao što je to

\footnotetext{
$4 \quad$ Termin parnjak ovdje označava svaki pojedini član para. No on može značiti i „,par”, odakle proizlazi mogućnost uspostavljanja distinkcije prema kojoj bi vidski par označavao „par nepravih parnjaka”, dok bi vidski parnjak označavao „par pravih parnjaka”. Ova ideja, koju su osmislili Cvikić i Jelaska (2007: 192), nije se dalje razvijala.

5 Jasno je da ovu vrstu situacije treba razlikovati od one u kojoj je naglasak nositelj značenjske razlike, primjerice u glagolima: nalàgati i nalágati, òbraniti i obrániti, itd. (Cf. Sekereš, Stjepan. „Razlikovna funkcija naglasaka u hrvatskom književnom jeziku", Jezik, Hrvatsko filološko društvo, 1 (1973/1974), str. 17-27).

6 Osim kod Raguža (2010: 187), ali bez jasno izrečene definicije.
} 
učinila Mršić (1999: 153), činjenica da su ti glagoli „,neodređeni” jer njihov vid u potpunosti ovisi o rečeničnom kontekstu.

Postojanje dvaju parnjaka u službi jednoga glagolskog pojma podrazumijeva da se njihova upotreba ostvaruje u opreci i da je uređena sustavom pravila. Ta pravila katkad određuje sintaksa, no najčešće su određena nepromjenjivim vrijednostima povezanim s jednim ili drugim vidom, a mogu i odražavati govornikov izbor kojim svoj iskaz najbolje prilagođava stvarnosti koju želi opisati. Međutim, važno je podsjetiti da izbor što ga vrši govornik nije niti slučajan niti onoliko subjektivan koliko se to tvrdilo (kao što napominje Kravar 1975), čak i ako pojedina sekundarna aspektna značenja (kao na primjer kod imperativa) mogu proizlaziti upravo iz govornikova osjećaja. Zbog toga, zajedno s Thomasom i Osipovim (2012: 280), nećemo zadržati „subjektivnu” definiciju vidskog para prema kojoj vidovi označavaju dva različita gledišta na istu stvarnost. Radije ćemo reći da se ovdje radi o opreci koja je oblikovana oko dvaju članova od kojih svaki prenosi nepromjenjive njemu svojstvene vrijednosti. Vidska opreka tradicionalno se smatrala privativnom, kao kod Bondarka (1971), što je potaknulo ideju da se ,nesvršenost najbolje određuje negativno u odnosu na svršenost”. ${ }^{7}$ Prema tom gledištu obilježeni parnjak u opreci jest svršeni, koji ima sposobnost izražavanja radnje „zamišljene u svojoj cjelovitosti” ili „sa svojim rezultatom”, dok bi se nesvršeni parnjak određivao negativno kao onaj koji označava radnju „bez upućivanja na cjelovitost”, „bez rezultata” (Thomas i Osipov 2012: 281).

Slijedit ćemo mišljenja jezikoslovaca (kao što su Avilova 1976, Gojmerac 1980, Thomas, Osipov 2012, Anissimova-Séville 2006) koji u vidskoj opreci prepoznaju ekvipolentan odnos, u kojemu je svakom članu naznačen i dodijeljen niz vlastitih osobina (njemu svojstvene nepromjenjive vrijednosti). Nažalost, ne slažu se svi autori oko prirode nepromjenjivih vrijednosti i njihove komplementarnosti.

U djelima posvećenima hrvatskome vidljiva je prevlast prikaza prema kojemu ,svršeni glagoli označuju cjelovitu radnju, dok se nesvršeni glagoli upotrebljavaju u slučaju procesualnosti i habitualnih događaja" (Brlobaš 2007: 27), no pritom se tu često upleće pojam trajanja radnje ili radnje ,u trajanju”. Tako prema Katičiću svršeni vid izriče radnje „,bez obzira na tijek vremena u kojem se odvijaju ili su smješteni u njemu”, koje se ,gledaju kao nedjeljiva cjelina jer

\footnotetext{
„Imperfectivity is best defined negatively with respect to perfectivity” (Weber 1978: 144).
} 
se zanemaruje vrijeme u kojem bi bili raspoređeni njihovi dijelovi", te koje su „skupljen[e] u jedno i obuhvaćen[e] od svoga početka do svojega kraja. Uzimaju se bez obzira na svoje trajanje" (Katičić 2002: 51), dok nesvršeni vid izriče radnje ,s obzirom na tijek vremena u kojem se odvijaju ili su smješteni u njemu. Tako izrečeni, gledaju se protegnuti u vremenu, pa se pozornost može usredotočiti na svaki njihov dio raspoređen u vremenskom tijeku” te ih prikazuje „kao djeljivo trajanje negdje između svojega početka i kraja, i uzimaju se upravo s obzirom na to trajanje" (Katičić 2002: 52). Moramo primijetiti da tako uspostavljen odnos između odvijanja radnje i njezina trajanja otvara vrata učestaloj pomutnji između procesualnosti, durativnosti i stvarne duljine radnje.

Opačić pak napominje da vidska opreka ne počiva na razlici između kratkog i dugačkog, kontinuiranog i isprekidanog, ograničenog i neograničenog trajanja, jer nesvršeni oblici ne izražavaju trajanje već vršenje radnje (Opačić 1978: 168). Za pretpostaviti je da jednako tako misle Težak i Babić kada pišu da ,[n]esvršeni glagoli izriču radnju koja u određenom vremenu još nije svršena. Svršeni glagoli izriču radnju koja je u određenom vremenu već svršena bilo u cjelini bilo samo djelomično" (Težak i Babić 2009: 139). Međutim, budući da ne navode u kojoj se točki vremena pojavljuje spomenuto „određeno vrijeme” (radi li se o vremenu iskaza ili o vremenu vršenosti?), oni iz svojeg opisa isključuju nesvršenu radnju koja je dosegla svoj kraj. Osim toga, ideja prema kojoj bi svršeni oblik mogao izražavati radnju čija je izvršenost ,samo djelomična” zbunjuje jer, ako ju shvatimo doslovno, ta bi tvrdnja mogla značiti da svršeni oblik može izražavati uzastopne etape radnje, što dovodi do pretpostavke da je svršena radnja djeljiva, a kao što smo ustvrdili ranije citiravši Katičića, djeljivost je, ako ne upravo glavno svojstvo, onda barem jedno od osnovnih svojstava nesvršenog oblika.

Nailazimo na vrlo slično objašnjenje te se susrećemo s istom poteškoćom kod Opačić koja primjećuje da ,svršeni glagoli izražavaju u potpunosti izvršenu radnju, bilo da se radi o cjelovitoj radnji izvršenoj od početka do kraja ili u samo jednom dijelu radnje". ${ }^{8}$ Moguće je pretpostaviti da se ova misao nadovezuje na definiciju koju daje Grubor kada piše da ,perfektivni glagoli razvojni znače potpunu izvršenost radnje ili bivanja od početka do kraja; cijele radnje ili određene količine” (Grubor 1953a: 8). Pojmovi „razvojni glagoli” i „,količina izvršene radnje" ni po čemu se ne suprotstavljaju značajki nedjeljivosti koja je svojstvena

\footnotetext{
8 „Perfective verbs express action as a completed whole, whether we are speaking of an entire action from the beginning to the end or only of a part of an action." (Opačić 1978: 166).
} 
svršenom obliku. Ne treba, naime, miješati značenjski sadržaj predikatne dopune s konceptualnim sadržajem svršenog oblika, koji izražava radnju koja ima završnu fazu. Ako parafraziramo primjer koji daje Grubor, možemo utvrditi da su, s gledišta aspektnog značenja, posve ekvivalentni iskazi Uzorao sam braz$d u$ i Uzorao sam njivu jer oba imaju završnu fazu, bilo da se radi o izvršenosti određene količine radnje (s dopunom brazda) bilo o izvršenosti cijele radnje (s dopunom njiva). Čini nam se da tu ideju prepoznajemo kod Webera (1978) koji predlaže to da, premda svršeni oblici izražavaju radnju izvršenu od početka do kraja, oni pak ne stavljaju veći naglasak na njezinu izvršenost, nego na neki drugi dio radnje zamišljene kao cjelina ${ }^{9}$. Utemeljenost tog mišljenja vidljiva je u situaciji kada pokušamo upotrijebiti priložnu oznaku za trenutnu radnju, kao u primjeru Pročitao sam knjigu / *Pročitao sam knjigu u 7 sati ujutro. (Weber 1978: 143).

Preuzevši taj primjer, možemo zajedno s Weberom ustvrditi da, ako kažemo Napisao je knjigu., svršeni oblik podrazumijeva svaku riječ i svaki redak koji je autor napisao, a ne samo trenutak u kojem je izjavio: „moja knjiga je završena”. No primijetit ćemo da dokazivanje pomoću vremenskog priloga ne vrijedi kod telične radnje, na primjer: Pokupio sam dijete u školi u 10 sati., što potvrđuje mišljenje da u proučavanju aspektnih značenja teličnost mora biti uzeta u obzir i jasno određena.

\section{Prijedlozi za usustavljenje terminologije aspektologije}

Ukratko, možemo zaključiti da se većina hrvatskih autora koristi nazivima nesvršenost/svršenost kako bi opisali opreku između stanja i radnje ili zbivanja te kako bi uputili na vidske osobine radnje. No, taj pojmovni par nama ne odgovara jer daje nesvršenosti negativne odlike, a mi želimo odrediti što ona jest, a ne što nije. Zato predlažemo nazive vršenost/izvršenost, slijedeći tako hrvatske jezikoslovce poput Grubora. Uz to ćemo uspostaviti vezu između radnje i pojma teličnosti, odnosno svojstvo radnje koja ima telos, to jest završnu granicu koja se ne može još jednom prijeći a da se radnja ne ponovi od početka (Sémon 1986).

\footnotetext{
9 Weber se ovdje oslanja na Comriejeva promišljanja: „It puts no more emphasis, necessarily, on the end of a situation than on any part of the situation, rather all parts of the situation are presented as a single whole" (Comrie 1976: 18).
} 
U općenitom smislu, ideja granice svojstvena svršenim glagolima vrlo se malo koristi iako ju Hamm smješta u središte vidske opreke „u kojoj se na protivnim stranama nalaze oblici koji označavaju radnju kao proces bez nekih granica, i oblici koji označavaju radnju kao proces vezan bilo početkom, bilo svršetkom, bilo inače (prostorno ili sl.) za takve granice" (Hamm 1967: 47). No, osim podosta neodređene riječi granica i njezinih derivata ograničenost, neograničenost (Čilaš Mikulić 2012) nije ponuđen niti prihvaćen nijedan naziv koji bi izrazio tu ideju. Time se promišljanje o vidu u hrvatskome lišava sredstava koja smatramo ključnima za opis aspektnih značenja i nepromjenjivih vrijednosti. Kako bismo popunili taj nedostatak, predlažemo uvođenje pojma međe koji bi zamijenio pojam granice, a čija je prednost ta da omogućuje stvaranje cjelovite leksičke mreže s nazivima omeđenost, neomeđenost, omeđiti, međna oznaka, lijeva međa, desna međa.

Nadalje, općenitom pojmu radnje, unutar kojeg razlikujemo tri vrste predikatnih situacija (stanje, aktivnost i događaj), pridodat ćemo pojmovni par ateličnost/ teličnost. ${ }^{10}$ Stanje izriče nedostatak promjene i postupnosti: sve su faze jednakovrijedne. Ono odgovara ateličnoj radnji koju možemo isto tako pojmiti kao globalno homogeni proces. Aktivnost izriče razvoj u tijeku, koji može i ne mora završiti telosom. Stoga ćemo s jedne strane razlikovati ateličnu aktivnost, a s druge aktivnost koja je omeđena, odnosno ima teličnu među. U oba slučaja radnja se može zamisliti kao homogena radnja sastavljena od niza heterogenih mikroradnja. Utvrdit ćemo pojmovnu i nazivnu razliku između aktivnosti koje predstavljaju niz mjerljivih mikroradnja, za koje ćemo reći da imaju postupni telos, ${ }^{11}$ te aktivnosti čije kretanje prema telosu nije mjerljivo, za koje ćemo reći da imaju konativno značenje. Događaj odgovara zatvorenoj, omeđenoj radnji čiji je telos smješten između nekog ,prije” i ,poslije” i koja mora imati završnu, odnosno desnu među (završnu granicu) te je možemo zamisliti i kao heterogenu radnju.

Važno je pojasniti da iako se svršenost najčešće pojavljuje zajedno s teličnošću, ona može isto tako izricati atelične glagolske pojmove. Desna međa svršene radnje tada ne mora biti naznačena telosom, u smislu neprekoračivog kraja prema kojem se radnja razvija, ali može biti u smislu moguće, potencijalne međe. Na-

\footnotetext{
10 Predloženi hrvatski ekvivalenti nezavršnost/završnost (Novak Milić 2010: 135) nisu se uvriježili.

11 Čineći ovu razliku, smatramo da se nadovezujemo na Gruborova razmišljanja, koji za nesvršene glagole koje naziva razvojnima uvodi sposobnost označavanja „etapa” radnje. Međutim, pojam „razvojni” koji on rabi ne prikazuje razine ostvarenja koje obilježavaju odvijanje radnje. Stoga predlažemo korištenje pojmova „postupnog telosa” i „postupne teličnosti”, koje nalazimo kod Jean-Paula Sémona i Svetlane Séville (2006).
} 
vedimo kao primjer sljedeći iskaz, koji objedinjuje tri moguće situacije, izrečene svršenim glagolom: Prehodala (aktivnost, radnja s postupnim telosom) sam cijelu Ilicu i pregledala (aktivnost, atelična radnja) sve izloge kako bih kupila (događaj, telična radnja) kaput koji ti se sviđa. Jedina osobina zajednička ovima trima svršenim oblicima je to da imaju završnu (desnu) među, koju možemo označiti generičkim nazivom međa svršenosti te se može primijeniti na sve tri vrste svršene radnje (Anissimova Séville 2006: 41).

Treba konstatirati da se pojmovi vršenost/izvršenost pokazuju nedostatnima za cjelokupni opis kompleksne vidske opreke. Kako bismo pravilno usmjerili opis aspektno-vremenskih značenja, čini nam se potrebnim raspolagati sredstvima kojima bismo mogli odvojeno pojmiti svaku pojedinu fazu (početnu - središnju - završnu) od kojih je sastavljena svaka radnja. Na temelju prethodno rečenog smatramo da jedino nesvršena radnja obuhvaća samo središnju fazu, dok jedino svršena radnja obuhvaća nadilaženje završne faze. Stoga ćemo, nadovezujući se na rad profesora Paul-Louisa Thomasa, prednost dati izrazu radnja zamišljena u središnjoj fazi (nesvršeni oblik), nasuprot radnji zamišljenoj sa završnom fazom ili sa završnom međom (svršeni oblik). Nadalje, za osnovnu definiciju vida preuzet ćemo onu prema kojoj nesvršeni vid predstavljanje radnje fokalizira na njezinu središnju fazu, dok svršeni vid predstavljanje radnje fokalizira na njezinu završnu među (cf. Thomas i Osipov 2012: 281). Takva formulacija jasno uspostavlja činjenicu da je svaki od članova vidske opreke obilježen te da se nalaze u ekvipolentnom odnosu.

Premda je istina da svaka radnja neizbježno posjeduje unutrašnje trajanje, ustanovili smo da se pojam trajanja ne može pojavljivati kao oznaka jednog vida (točnije nesvršenog) više nego drugog. Dakle, ne uzimamo u obzir trajanje kao nepromjenjivu vrijednost nesvršenog oblika, već pribjegavamo pojmu durativnosti kako bismo imenovali uzimanje u obzir samo središnje faze radnje.

\section{Zaključak}

Možemo zaključiti da smo, s obzirom na relativan nedostatak istraživanja koja proučavaju vid i aspektna značenja u radovima hrvatskih jezikoslovaca, svoje istraživanje provele bez bojazni da ćemo se suprotstavljati već utvrđenim stajalištima. Čini nam se da smo u ovom radu uvele korisne i, s hrvatskog gledišta, 
nove opisne elemente tako što se jasnije određuju vrste radnje (stanje/aktivnost/ događaj), uključuju koncepti glagolskog pojma i teličnosti, predlaže pojam međe, preoblikovanje razlikovanja svršene i nesvršene radnje te naposljetku predstavlja ekvipolencija vidske opreke.

\section{Literatura:}

Anissimova-Séville, Svetlana. 2006. Aspect de l'infinitif dépendant des auxiliaires de vouloir, pouvoir et devoir en russe moderne. Doktorski rad. Université Paris IV-Sorbonne, Paris. 552 str.

Avilova, NatAl'JA. 1976. Vid glagola i semantika glagol'nogo slova. Nauka. Moskva. (ćirilica)

Babić, StJepan; TežAK, StJePKo. 2009. Gramatika hrvatskoga jezika, priručnik za osnovno jezično obrazovanje. 17. izd. Školska knjiga. Zagreb.

BABIĆ, StJePAn I DR. 2007. Glasovi i oblici hrvatskoga književnoga jezika. Nakladni zavod Globus. Zagreb.

BARIĆ, EugeniJa I DR. 2005. Priručna gramatika hrvatskoga književnoga jezika. Zavod za jezik instituta za filologiju i folkloristiku. Školska knjiga. Zagreb.

Bondarko, Aleksandr V. 1971. Vid i vremja russkogo glagola. Prosvešćenije. Moskva. (ćirilica)

BRLOBAŠ, ŽELJKA. 2007. Glagolski vid u hrvatskim gramatikama do 20. stoljeća. Institut za hrvatski jezik i jezikoslovlje. Zagreb.

Cvikić, LidiJa; Jelaska, Zrinka. 2007. Složenost ovladanja glagolskim vidom u inojezičnome hrvatskome. Lahor 4. 190-216.

ČIlaš Mikulić, MaricA. 2012. Glagolski vid u hrvatskome kao drugome i stranome jeziku. Doktorski rad. Filozofski fakultet. Zagreb.

Gojmerac, Mirko. 1980. Glagolski vid u hrvatskom ili srpskom i njemačkom jeziku. Doktorski rad. Filozofski fakultet. Zagreb.

Grubor, Đuro. 1953a. Aspektna značenja I. Rad JAZU 293. Zagreb.

Grubor, Đuro. 1953b. Aspektna značenja II. Rad JAZU 295. Zagreb.

HАмм, Josip. 1967. Kratka gramatika hrvatskosrpskog književnog jezika za strance. Školska knjiga. Zagreb.

JONKE, LJUDEVIT. 1964. Kratka gramatika hrvatskosrpskog književnog jezika: uz audiovizuelni tečaj. Zavod za fonetiku Filozofskog Fakulteta u Zagrebu. Zagreb.

Katičić, Radoslav. 2002. Sintaksa hrvatskoga književnog jezika (3. poboljšano izdanje). HAZU - Nakladni zavod Globus. Zagreb. 
Kravar, Miroslav. 1957. O vidu defektivnog glagola velim. Jezik 5/3. 81-82.

Kravar, Miroslav. 1975. Glagolski vid kao tipološko-komparativni problem. Radovi Filozofskog fakulteta u Zadru, Razdio lingvističko-filološki 14/15. Sveučilište u SplituFilozofski Fakultet Zadar. 289-312.

Mønnesland, Svein. 2003. Glagolski vid u hrvatskom jeziku. Ur. Botica, Stipe. Zbornik Zagrebačke slavističke škole 2002. FF press. Zagreb. 21-31.

Mršić, Tinana. 1999. Dubinska dihotomija trenutačno: protežno i glagolski vid. Filologija 32. 145-155.

NovaK MiLić, JaSna. 2010. Što je što u aspektologiji ? Lahor 10. 125-143.

OpAČIĆ, Nives. 1978. Verbal Aspect in the Contemporary Serbo-Croatian Literary Language. Ur. Filipović Rudolf. Contrastive Analysis of English and Serbo-Croatian: a) Verbal Aspect, b) Word Order. Zagrebački kontrastivni projekt engleskog i hrvatskog ili srpskog jezika II. Zavod za lingvistiku. Zagreb. 162-168.

Pranjković, Ivo. 2003. Glagolske kategorije prema imenskima. Ur. Botica, Stipe. Zbornik Zagrebačke slavističke škole 2002. FF press. Zagreb. 9-15.

Raguž, Dragutin. 2010. Gramatika hrvatskoga jezika. Vlastito izdanje. Zagreb.

Sémon, Jean-Paul. 1986. 'Postojat' ou la perfectivité de congruence, définition et valeurs textuelles. Revue des Etudes Slaves 58/4. 609-635.

Silić, Josip; Pranjković, Ivo. 2005. Gramatika hrvatskoga jezika za gimnazije i visoka učilišta. Školska knjiga. Zagreb.

Thomas, Paul-Louis; Osipov, Vladimir. 2012. Grammaire du bosniaque croate monténégrin serbe. Institut d'Etudes slaves. Paris.

Weber, Ralph. 1978. Aspect in Serbo-Croatian and English. Ur. Filipović, Rudolf. Contrastive Analysis of English and Serbo-Croatian: a) Verbal Aspect, b) Word Order. Zagrebački kontrastivni projekt engleskog i hrvatskog ili srpskog jezika II. Zavod za lingvistiku. Zagreb. 140-157.

\section{A small step towards the systematization of the terminology of aspect in the Croatian language}

\section{Abstract}

Numerous works devoted to the verbal aspect in the Slavic languages, as well as in other languages in which this category is not morphologically marked, have produced an abundance of terms, that is, terminological systems that vary, depending on a particular description. This abundance, encouraged by the progress of research, but also by the personal work of linguists dealing with different language families, has produced ambiguities that are obstacles to the development of aspectology and which 
are maintained in the very core of the Croatian language terminology (Novak Milić 2010: 131). In the tradition of works describing verbal and aspectual meanings in Slavic languages, certain terminological pairs commonly appear, describing ways of doing things such as "duration / punctuality", "performing / accomplishment" etc. Newer terms, which are the fruits of personal work or which stem from the tradition of language schools, do not necessarily have the same meaning in the works of all the authors who use them. However, with the exception of the few articles describing some topics (Mršić 1999, Novak Milić 2010), no author after Đuro Grubor $\left(1953_{\mathrm{a}}, 1953_{\mathrm{b}}\right.$ ) has attempted to elaborate a complete terminology that would meet the needs for describing aspects in Croatian. We assume that a systematized terminology would create a basis for deeper study of verbal aspect and, in general, aspectology, and would help to improve research on that subject in Croatian. This leads to the need for reviewing the existing terms and definitions of the concepts that they signify, so that we can offer a precise basic terminology as an incentive to continue the research on aspectology. In the first part of our work, we will provide an overview of the terms and concepts used so far in the works devoted to verbal aspect. In the second part, we propose a set of terms and harmonized definitions of designated concepts. We will try to introduce useful and, from the Croatian point of view, new descriptive elements by specifying the types of actions (state / activity / event) more clearly, including concepts of aspectual value, verb meaning and telicity, proposing to redefine the distinction between perfective and imperfective actions and ultimately representing equipollency of aspectual oppositions.

Ključne riječi: aspektologija, glagolski vid, svršenost, nesvršenost, aspektna značenja Keywords: aspectology, verbal aspect, perfectivity, imperfectivity, aspectual values 